\title{
Moral Hazard and Safety Regulation
}

\author{
Ingemar Hansson and Göran Skogh*
}

\section{Introduction}

Risky activities give rise to two fundamental economic problems; externalities and uncertainty. Under conditions of zero transaction costs, these problems can be eliminated by liability rules and insurance. In a world with transaction costs including imperfect information gains from regulation of externalities may counteract gains from insurance. If externalities are fully internalised by making the injurer fully liable, a risk adverse injurer may suffer substantially because of an uncertain outcome. If, on the other hand, the ill effects of an uncertain outcome are eliminated by means of insurance, the externality reappears because the insurer cannot fully control the behaviour of the injurer. A compromise between externality regulation and insurance can be obtained by private market or public institutions of liability rules, insurance, regulation and punishments.

Economic analyses often treat externality control and insurance as separate problems in spite of their close relationship. For instance, analyses of environmental hazards and product liability normally assumes risk-neutral agents and thus excludes insurance aspects. Even if externality control is introduced, disobeyance of public regulations is typically ignored. Disobeyance of laws is instead studied separately as the economics of crime (Becker 1968). Similarly, the insurance literature often neglects problems of regulation and compliance.

This paper analyses the conflict between externality control and insurance when information is imperfect. We examine both a private market system with liability and insurance and a public system with insurance and regulation upheld by the random punishment of

* Department of Economics, University of Lund. Thanks are due to Hugh Gravelle and Charles Stuart for helpful comments. Financial support from the Bank of Sweden Tercentenary Foundation and the Swedish Council for Research in Humanities and Social Sciences is gratefully acknowledged. 
offenders. We extend earlier studies in two ways. ${ }^{1}$ First, we examine resource allocation when the insurer can reduce moral hazard by regulating behaviour. Second, we examine public insurance and regulation when information is imperfect. This includes an explicit analysis of compliance and the simultaneous determination of optimal legal standards and optimal punishments.

The paper is organised as follows. In section 2, we present the model. There, we analyse first the case when the costs of accidents are covered by tort-liability with and without insurance. Thereafter, we study public insurance and regulation enforced by punishment. In section 3 , we discuss the shortcomings of tort-liability and of regulation. We find that regulation is both a complement to as well as substitute for partial cost-liability. Finally, in section 4 , there is a summary.

\section{The model}

We formally examine a private market system of liability, possibly supplemented with competitive voluntary insurance, as well as a public system with compulsory insurance supplemented with regulation and punishment. The individual's optimal behaviour in each system and the optimal public policy is analysed. In order to aid intuitive interpretations, the discussion deals with the special case of traffic accidents, but the analysis can be generalised to apply to most types of accidents and most external effects.

We assume that individuals are going to travel a given distance and that the only relevant control variable is the travelling time, which is chosen by the individual. At a given speed, the travelling time equals the distance divided by the speed. For simplicity, the control variable $X$ is defined as the actual travelling time in excess of the travelling time that is optimal for the individual when he neglects effects on other individuals. Hence the individually optimal $X$ equals zero. Imperfect information is introduced by the assumption that only the individual himself can observe $X$ without costs.

An accident gives costs or losses of $L$ for other individuals. We simplify by ignoring accident costs that may arise for the individual controlling the safety measure $X$. The probability of an accident depends on the travelling time $0 \leqslant \mathrm{P}(X)<1$. This function is twice continuously differentiable with $P^{\prime} \equiv d P / d X<0, P^{\prime} \rightarrow-\infty$ as $X \rightarrow 0, P^{\prime} \rightarrow 0$ as $X \rightarrow \infty$ and $P^{\prime \prime} L O$. An example is shown in figure 1.

1 A selected list of the literature relevant to this problem follows. Shavell (1979a) analyses optimal insurance when information is imperfect. Calabresi (1970) examines tort-liability with private insurance and public regulation with compensation of accidents. Wittman (1977) presents in general terms the comparative benefits and costs of regulation versus liability. Polinsky and Shavell(1979) analyse the optimal tradeoff between the probability and magnitude of fines. By assuming risk-averse offenders as well as victims, they include insurance. Göran Skogh and Charles Stuart (1977) and Shavell (1979b) compare public insurance, tort-liability and private insurance. In "Public Insurance and Accident prevention" Skogh (1982) compares taxes, tort-liability and regulations upheld by punishments. Shavell (1984a) analyses the optimal use of liability and safety regulation. 


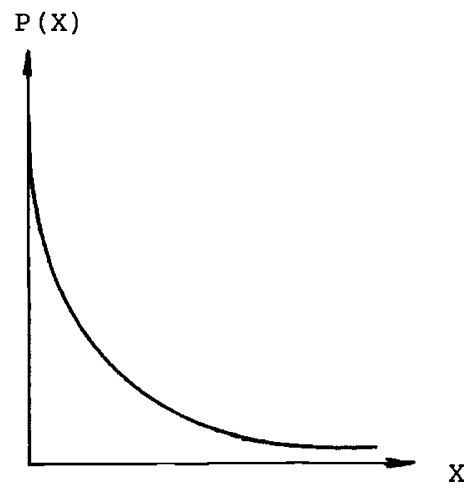

Figure 1.a: Relation between probability of an accident and travelling time

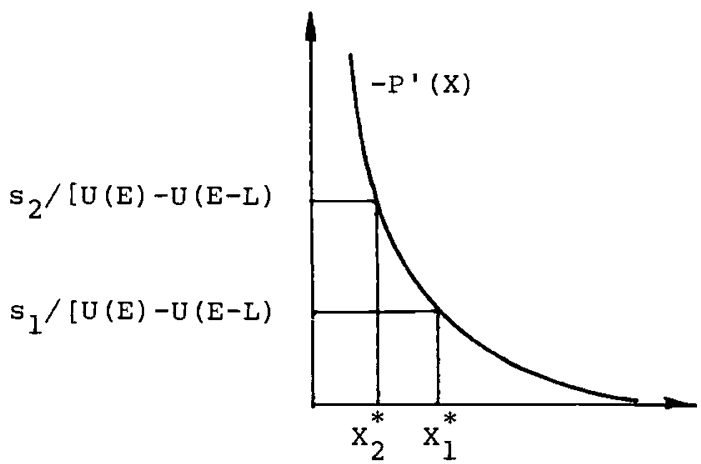

Figure 1.b: Determination of optimal travelling time

We assume there are two homogenous group of individuals, $i=1,2$, which are identical except for a difference in their subjective cost of time (in excess of their common individually optimal time). Because of imperfect information, only the individual himself knows whether he belongs to group 1 or 2 . More specifically, the expost utility of group $i$ is represented by the utility function.

$$
U(C)-s_{i} X
$$

where $C$ is consumption and $s_{i}$ is the subjective cost of time for group $i$, where $s_{1}<s_{2}$. The assumptions in (1) of separability between $C$ and $X$ and of a constant marginal utility of $X$ are to simplify the analysis. The first term in the utility function is twice continuously differentiable with $U^{\prime}>0, U^{\prime \prime}<0, U^{\prime} \rightarrow \infty$ as $C \rightarrow 0$, and $U^{\prime} \rightarrow 0$ as $C \rightarrow \infty$. Figure 2 provides an example.

\subsection{Private solution with liability and insurance}

The fundamental problem of liability and safety regulation is that an individual may neglect the external effects of his own behaviour on others in the absence of any type of regulatory mechanism. The traditional solution to this problem is to place all accident costs on the party that controls the safety-measure $(X)$. In accordance with earlier literature, we assume that this can be accomplished via a strict liability system at negligible transaction costs. Later, we argue that this often is an inadequate assumption.

We also assume that each individual has an exogenous endownment $(E)$ that exceeds the other individuals' accident costs $(L)$. An individual's consumption equals his endownment if no accident occurs and equals $E-L$ if an accident occurs. Group $i$ selects its travelling time to maximise expected utility:

$$
\text { Maximise } U(E)\left(1-P\left(X_{i}\right)\right)+U(E-L) P\left(X_{i}\right)-s_{i} X_{i} \text {. }
$$


The solution is interior with first-order condition:

$$
\begin{aligned}
& -U(E) P^{\prime}\left(X_{i}\right)+U(E-L) P^{\prime}\left(X_{i}\right)-s_{i}=0 \text {, or } \\
& -P^{\prime}\left(X_{i}\right)=s_{i} /[U(E)-U(E-L)] .
\end{aligned}
$$

This condition determines a unique optimal value for the travelling time, $X_{i}^{*}$, as is illustrated in figure 1.b. Because the right hand side of $(3 \mathrm{~b})$ is the same for both groups it follows that $X_{1}^{*}$ $>X_{2}^{*}$. That is, individuals with lower subjective costs of time $\left(s_{1}<s_{2}\right)$ select a longer travelling time. $^{2}$

The facts that individuals are risk-averse and consumption randomly equals $E$ or $E-L$ means that the outcome with liability is not an overall first-best outcome. This is demonstrated in figure 2. The expected utility from private consumption is $U(E)\left(1-P\left(X_{i}^{*}\right)\right)+U(E-$ $L) P\left(X_{i}^{*}\right)$, which is the height of the straight line in figure 2 at expected consumption, $E$ $P\left(X_{i}^{*}\right) L$. Due to risk-aversion, expected utility is less than the utility of expected consumption.

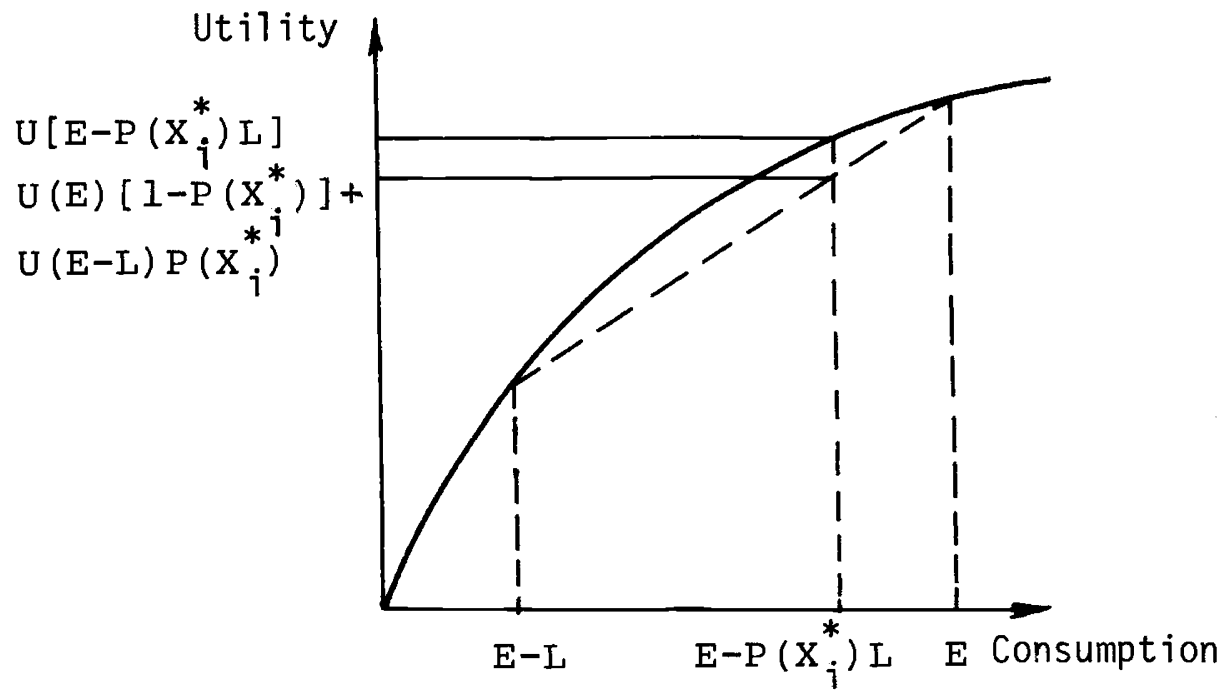

Figure 2: Utility from private consumption

We now examine the first-best allocation and the (additional) information that is required in order to obtain this solution with private insurance. The first-best-allocation, $X_{i}^{* *}$, is determined by maximisation of:

$$
U\left(E-P\left(X_{i}\right) L\right)-s_{i} X_{i} .
$$

2 This conclusion is due to the simple separable utility function (2). If the subjective cost of travelling is instead assumed to be a perfect substitute to private consumption, the result need not hold. 
The first-order condition is:

$$
\begin{aligned}
& U^{\prime}\left(E-P\left(X_{i}\right) L\right)\left(-P^{\prime}\left(X_{i}\right) L\right)-s_{i}=0, \text { or } \\
& -P^{\prime}\left(X_{i}\right)=s_{i} / U^{\prime}\left(E-P\left(X_{i}\right) L\right) L
\end{aligned}
$$

In order to examine the relation between $X_{i}^{*}$ and $X_{i}^{* *}$, note that (3b) and (5b) imply

$$
\text { - } P^{\prime}\left(X_{i}^{*}\right)[U(E)-U(E-L)] / L=-P^{\prime}\left(X_{i}^{* *}\right) U^{\prime}\left(E-P\left(X_{i}^{* *}\right) L\right) .
$$

The last factor on the left-hand side of $(6)$ is the slope of the straight line between $U(E)$ and $U(E-L)$ in figure 2 . The last fact or on the right-hand side is the slope of the utility function at consumption level $E-P\left(X_{i}^{* *}\right) L$. If $P(X)$ is small, expected consumption is relatively close to $E$ (see figure 2). This in turn implies that the last factor on the right hand side of (6) is smaller, or $-P^{\prime}\left(X_{i}^{*}\right)<-P^{\prime}\left(X_{i}^{* *}\right)$, so $X_{i}^{*}>X_{i}^{* *}$. Thus travelling time when an individual faces liability without insurance exceeds first-best travelling time. People optimally select less care when they face the expected value but not the risk associated with accidents.

Utility is obviously higher in the first-best allocation than if there is liability without insurance, because both the elimination of uncertainty and the adjustment from $X_{i}^{*}$ to $X_{i}^{* *}$ increase utility (see figure 2).

The first-best allocation would require an insurance premium $P\left(X_{i}^{* *}\right) L$ and travelling time $X_{i}^{* *}$ for group $i$. By assumption, nobody but the individual can observe $X_{i}$ without costs. If these costs are prohibitive for a private insurer, the insured individual has no incentive to select $X_{i}^{* *}$. A fully insured individual facing an exogenous actuarially fair insurance premium instead maximises

$$
U(E-\Psi)-s_{i} X,
$$

where $\psi$ is the insurance premium which is given for any single individual. This implies that he selects $X_{i}=0$, which is the well-known problem of moral hazard. Selecting $X_{i}=0$ may be interpreted as an external effect because the injurer imposes costs on the insurer. The introduction of insurance with imperfect information thus reintroduces the problem of externalities. This illustrates the conflict between controlling externalities and providing insurance when information is imperfect.

When information is costly, the first-best allocation cannot be obtained. The compromise between the control of externalities, insurance and information costs may then be viewed as a problem of second-best. This includes a choice between private market and public solutions.

To start with private market solutions, Shavell (1979a) examines the case of prohibitively costly information and shows that the optimal compromise between the control of externalities and insurance implies that the injurer bears part of accident costs.

If information costs are not prohibitive, the insurer can affect $X$ in different ways. While many different methods can be and are actually used, we limit the analysis to one empirically relevant example. We assume that the insurer can state that the insurance does not apply if the accident is due to reckless driving, i.e., if $X_{i}$ is less than a certain limit, $X^{\not t}$, but 
that such a rule introduces information costs. In order to simplify, we assume that the insurance cover all accident costs if adequate care is taken. The individual then optimises:

$$
\begin{aligned}
& \text { maximise } U(E-\Psi)\left(1-D\left(X_{i}\right)\right)+\left[U(E-\Psi)\left(1-P\left(X_{i}\right)\right)+\right. \\
& \text { where } D\left(X_{i}\right)=\left\{\begin{array}{l}
0 \text { if } X_{i} \geqslant X^{\#} \\
1 \text { if } X_{i}<X^{\#,}
\end{array}\right.
\end{aligned}
$$

where $\psi$ is an actuarially fair insurance premium which is given for any individual and which includes information costs per insured individual denoted $I$. In a competitive insurance market, the insurers will supply insurance policies with different levels of the limit $X^{\sharp}$ at actuarially fair premiums which include $I$. If $I$ is sufficiently high, nobody would insure in equilibrium. If $I$ is lower, individuals in exactly one of the groups may find it advantageous to be insured. The individuals in this group will select, from among the insurance contract offered, a level of $X^{\#}$ that maximises utility given that $X_{i}=X^{\#}$ and that consumption equals $E$ $P\left(X^{\sharp}\right) L-I$. The third possible alternative is that both groups buy insurance. Because the subjective cost of time is higher for group 2 than for group 1 , the limit for minimum time $\left(X^{\#}\right)$ will be lower in group 2's insurance than in group l's insurance. For the unrealistic case of zero information costs, the equilibrium would give rise to the first-best allocation, $X_{i}=X_{i}^{* *}$ for $i=1,2$.

Note that the problem of adverse selection does not arise here in spite of the assumption that the insurer cannot distinguish between the two groups. This is because individuals classify themselves by choosing one of the two competitive insurance policies. Note also that the insurance policy includes a mechanism of regulation and enforcement. In this example, the policy holder is encouraged to select the optimal travelling time by the insurer's right to withhold the claim in the event of "reckless driving".

Due to administrative costs, the outcome in all three possible cases is suboptimal compared to the first-best allocation. If at least one group is insured, the private solution includes information costs. If at least one group is not insured, uncertainty remains.

\subsection{Public insurance, regulation, and punishments}

When information is imperfect, a private market solution does not generally imply a first-best allocation. In Shavell's (1979a) model, the private market equilibrium includes suboptimalities in the form of remaining uncertainty and externalities. Analogously, our model of private insurance implies remaining uncertainty or information costs. We now model a public system of insurance and regulation as an alternative second-best solution. This solution differs from the private market solution because government can use a number of coercive measures not available to a private insurer such as compulsory insurance, taxes, supervision and punishments. ${ }^{3}$

\footnotetext{
${ }^{3}$ Gravelle (1987) examines whether the government can improve an equilibrium in a private insurance market with imperfect information by using taxes that cannot be used by private insurers.
} 
In the absence of information costs, the authorities impose compulsory insurance, regulate the behaviour of each individual to the first-best optimal level, and enforce regulation with sufficiently severe punishments. As was the case for the private system, this would yield the first-best allocation given the unrealistic assumption of zero information costs.

We now examine one of many possible public systems of insurance and regulation. As before we assume that the control variable, $X$, cannot be observed without costs and that the authorities cannot determine whether an individual belongs to group 1 or 2 . We assume that the public sector bears all accident costs. To alleviate the problem of moral hazard, the public sector attempt to influence $X$ by regulating behaviour and, consequently, punishing offenders. More specifically, we examine the empirically relevant case in which the government sets a uniform legal standard $X^{+}$, and imposes a punishment $A$ for each detected offender. More specifically, $X^{+}$is the minimum travelling time required according to legal speed limits and $A$ is the punishment for speeding. To deal simply with the problem of imperfect information, we assume that the probability of detection, $\Pi<1$, is exogenous and that the public system of inspection and administration gives rise to constant per-capita government transactions costs, $G$. These costs include inefficiencies that may arise due to the absence of competition between different insurers in a public system.

For simplicity we assume that the punishment is non-monetary and separable in utility. This means that punishments are costly per se as opposed to the more traditional but perhaps empirically less relevant assumptions of monetary punishments. The costs of accidents as well as transaction costs are financed by a lump-sum insurance premium or tax, $T$. Individual $i$ maximise expected utility:

$$
U(E-T)-s_{i} X_{i}-\Pi A \delta\left(X_{i}\right),
$$

$$
\text { where } \delta\left(X_{i}\right)=\left\{\begin{array}{c}
0 \text { if } X_{i} \geqslant X^{+} . \\
1 \text { is } X_{i}<X^{+} .
\end{array}\right.
$$

The relation between travelling time and expected utility given by the program (9) is illustrated in figure 3 .

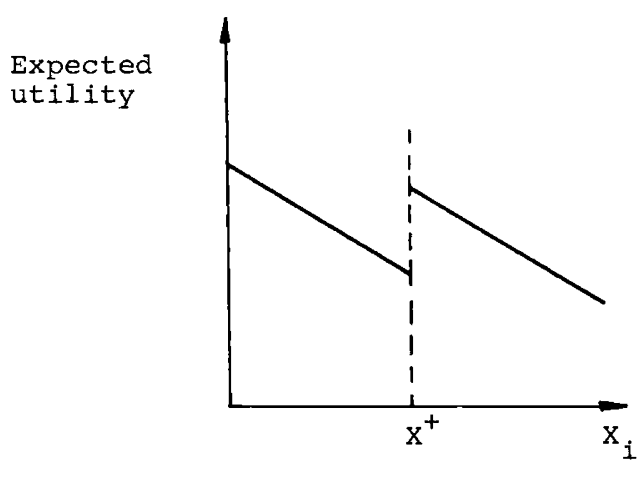

Figure 3 
In the interval $\left[0, X^{+}[\right.$, travelling time is less the time required by legal speed limits, hence the individual does not comply. Because the punishment $A$ is independent of the care taken, $X=0$ is the best choice (see (9)) in that interval. At $X^{+}$, utility jumps to a higher level because travelling time now is long enough to avoid punishment. Obviously, $X^{+}$is best in the interval $X \geqslant X^{+}$. The only candidates are hence the individually optimal time $X=0$ and the legal limit $X=X^{+}$. The choice obviously depends on the policy variables $X^{+}$and $A$, the lump-sum $T$, and the individual's subjective valuation of time $s_{i}$.

Note that a higher valuation of time boosts expected utility at $X=0$ more than it boosts expected utility at $X=X^{+}$, which makes $X=0$ relatively more attractive. Because $s_{1}<s_{2}$, this means that group 2 selects $X=0$ if group 1 selects $X=0$. The only three possible outcomes under regulation are thus $(0,0),\left(X^{+}, 0\right)$ and $\left(X^{+}, X^{+}\right)$, where the two arguments represent group l's and group 2's optimal travelling times.

Suppose the government is benevolent and maximises social welfare defined as a weighted average of the two groups' utilities, where the weight $\gamma$ for the first group represents the relative size of this group. It solves

$$
\begin{aligned}
& \text { maximise } U(E-T)+\gamma\left[-s_{1} X_{1}-\Pi A \delta\left(X_{1}\right)\right]+(1-\gamma)\left[-s_{2} X_{2}-\Pi A \delta\left(X_{2}\right)\right], \\
& \left\{X^{+}, A\right\} \\
& \text { where } \\
& T=\left[\gamma P\left(X_{1}\right)+(1-\gamma) P\left(X_{2}\right)\right] L+G, \\
& X_{i} \text { are determined by individual } i \text { 's maximisation (9) for } i=1,2 .
\end{aligned}
$$

Figure 4.a summarises the two individuals' responses to different values of the policy instruments $A$ and $X^{+}$. To examine the optimal solution, suppose first that $A$ is held constant at its optimal level, $\hat{A}$, and let the minimal allowed travelling time, $X^{+}$, vary as is shown in figure 4.a.

For a sufficiently high $X^{+}$, no group will comply, i.e., the outcome is $(0,0)$ as in figure $4 . a^{4}$ Decreasing the limit $X^{+}$eventually leads to a point where group 1 shifts to compliance, because the adjustment of $X$ from 0 to $X^{+}$is then advantageous compared to punishment for this group. This is marked by the curve that separates the $(0,0)$ and the $\left(X^{+}, 0\right)$ regions in figure 4.a. A single individual in group 1 is indifferent between 0 and $X^{+}$at the border between these two regions. The upward shift in $X_{1}$ decreases the probability of accidents for group 1 , however, and thereby decreases the lump-sum $T$. This is gainful for all individuals so social

${ }^{4}$ A decrease in $X+$ in this interval has no effect on $X_{1}$ and $X_{2}$ and hence no effect on social welfare as specified in (10). This is shown by the vertical line in figure $4 . b$. 


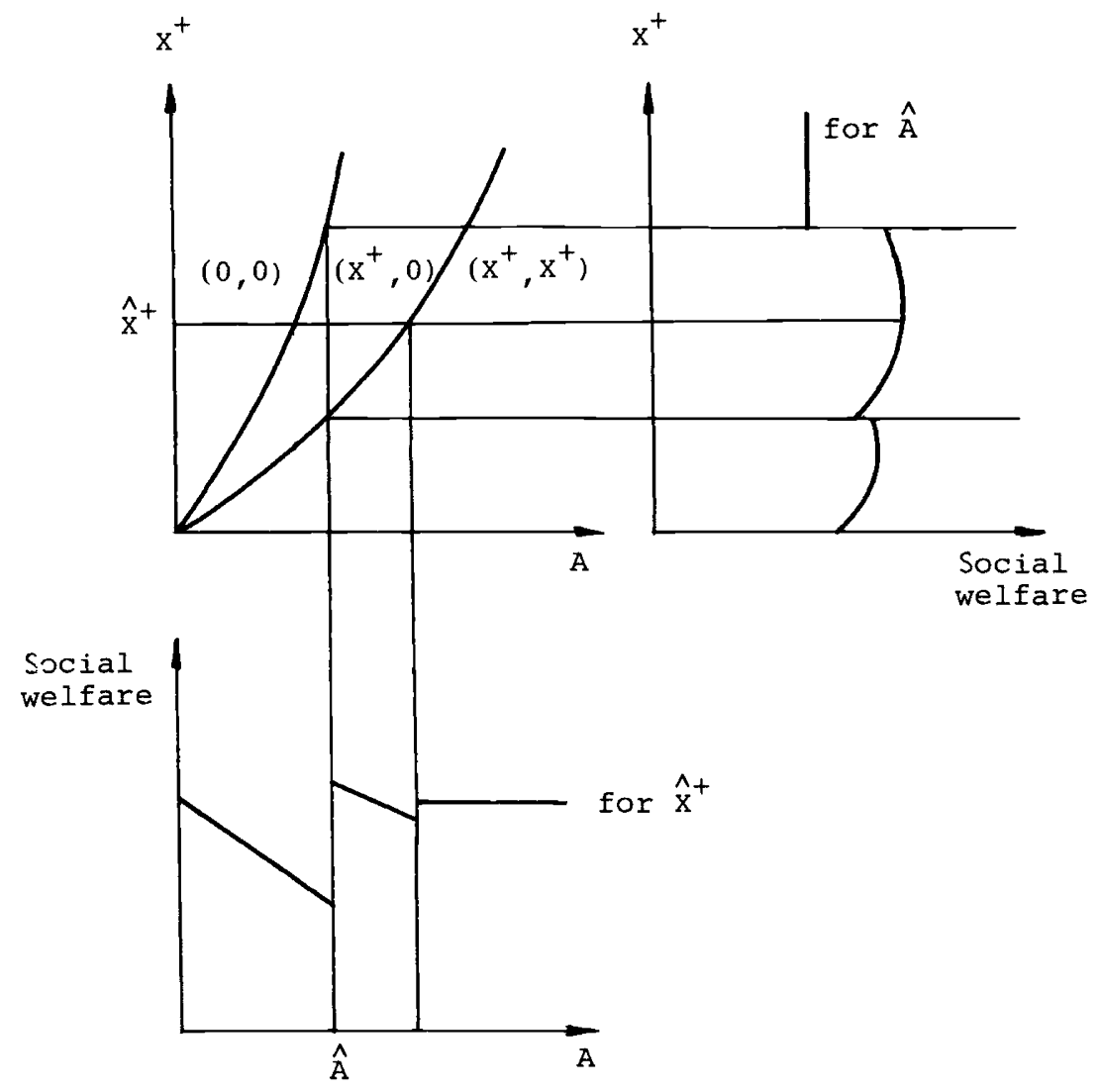

Figure 4.c

welfare shifts upwards when $X_{1}$ shifts from 0 to $X^{+}$(see figure 4.b. $)^{5}$ Because social welfare is constant in the interval in which nobody complies but shifts upwards at the lower border, the optimal solution cannot lie in this interval. This means that the legislated minimum time should never be set so high that nobody complies.

\footnotetext{
${ }^{5}$ This shift to a higher $X$ influences social welfare (10) in three ways. First, a higher $X$ decreases $P\left(X_{1}\right)$, which yields a downward shift in $T$ that in turn causes an upward shift in the first term in (10a). Second, the increase in $X$ decreases the second term, which tends to decrease social welfare. Third, the induced shift from $\delta\left(X_{1}\right)=1$ to $\delta\left(X_{1}\right)=0$ increases the third term, because socially costly punishments are avoided for group 1. By the envelope theorem, the second and third effects are exactly balanced when the individual shifts from $X_{1}=0$ to $X_{1}=X_{1}^{+}$, which implies that the first effect remains and shifts social welfare upwards.
} 
Within the interval where only group 1 complies, the policy variable $X^{+}$in effect determines $X_{1}$, while $X_{2}$ remains zero. For a sufficiently low $X^{+}$, group 2 also complies. The shift from $X_{2}=0$ to $X_{2}=X^{+}$analogously shifts social welfare upwards. In figure 4.b, social welfare is maximised in the interior of the interval where only group 1 complies. This means that the optimal law here regulates group l's behaviour only with group 2 not complying. However, this is only one of several possibilities. Generally, the optimal value of $X^{+}$is at the upper border or in the interior of the interval where only group l complies or at the upper border or in the interior of the interval where both groups comply. The laissez-faire solution $X^{+}=0$ cannot be socially optimal when accident costs and fixed transaction costs are financed by lumpsums, because a slight increase in $X^{+}$would increase social welfare.

We next examine necessary conditions for the punishment $A$ when the legal time limit is held constant at the optimal value, $\hat{X}^{+}$. As illustrated in figure 4.a, zero punishment $(A=0)$ implies that both groups select $X=0$. With a sufficiently high $A$, group 1 complies, i.e., the outcome is $\left(\hat{X}^{+}, 0\right)$. With a still higher $A$, both groups comply. As before, the optimal solution cannot be in the interval where $X_{1}=X_{2}=0$ when transaction costs are fixed. An increase in $A$ within the interval where only group 1 complies does not affect behaviour but is socially harmful per se and, therefore, decreases social welfare. At the point where $A$ is high enough to yield lawful behaviour for both groups, social welfare shifts upwards. Social welfare is therefore a maximum at the level of $A$ either where group 1 just complies, or at the level of $A$ where group 2 just complies. The advantage of the first outcome is that group 1 chooses a socially optimal level of $X_{1}$ and the disadvantage is that group 2 is punished because it selects $X_{2}=0$. The advantage of the second outcome is that nobody is punished and the disadvantage is that all individuals are induced to select the same value of $X$ in spite of differences in the subjective costs of time. ${ }^{6}$ The relative performance of these two alternatives depends on the difference between the two groups costs of time and the share of group $1, \gamma$. If $s_{1}$ is sufficiently close to $s_{2}$, the disadvantage of a uniform $X$ is slight, so forcing both groups to comply is socially optimal. On the other hand, if $\gamma$ is sufficiently large, the social benefit of regulation of group 1 dominates, so the optimal law is primarily designed to give adequate precaution by the majority. If $s_{2}$ greatly exceeds $s_{1}$, the minority does not comply here and is therefore punished. Consequently, if it is not possible to differentiate legal limits because of imperfect information, it may be socially optimal to accept costly punishment of offenders even though their behaviour is not affected in order to induce proper precautionary behaviour by the majority. Actual systems of regulation fit this picture.

\footnotetext{
${ }^{6}$ Individuals in equilibrium can be identified by their travelling times (or speeds). This information cannot, however, be used to avoid punishment because an attempt to do so would eliminate incentives for members of group 1 to obey the law.
} 


\section{Discussion}

The relative performance of the examined private market and public systems of insurance and regulation in section 2 generally depends on 1 . information and transaction costs in different systems ( $I$ and $\mathrm{G}$ in the models), 2. the relation between the control measure and the probability of an accident $(P(X)), 3$. the magnitude of accident costs or liability $(L), 4$. the share of group $1(\gamma)$, and 5 . the degree of risk aversion. A more detailed analysis of the relative performance of the two systems in specific cases lies outside the scope of the current paper. ${ }^{7}$

In addition to the examined information costs, private market solutions give rise to further problems. The private market system of cost-liability and insurance in section 2 . requires that accident costs can be measured and disaggregated among injurers for each single accident. In the real world, such identification and measurement is typically costly, which is a fundamental reason for the existence of an externality. Costs of accidents are then sometimes borne by the public randomly, by victims' insurances, or by the public sector as a part of government expenditures on health care and pensions. As well, taxation of income and consumption means that the public sector bears a large part of accident costs that decrease taxable factor income.

An additional problem for the examined private market system is that there often exists some risk-sharing arrangements that cannot easily be eliminated when cost-liability and private insurance are introduced. The clan, the guild or the family diversify risks in a way that may prevent the introduction of full liability. Such collective risk-sharing may exhibit a substantial degree of inertia and may fulfill important social functions. A public system can be designed to take account of such pre-existing types of insurance schemes.

A further complication of reliance solely on private liability is that an accident typically is result of interactions among individuals; Coase (1960). When many agents are involved, the actions of many agents may cause the accident but the causalty may be very complicated to "settle". Who causes, for instance, an accident at sea? The captain, the crew, the radio station that reported a misleading weather-forecast, the public control agency that accepted an incorrect sea-map, or the firm that installed a deviating auto-pilot? The answer may be that all contribute but that the marginal impact of each party is difficult, if not impossible, to identify in each single accident.

Shavell (1980) noted that a system of full liability for each of the agents involved would provide proper incentives when some controls (the activity levels) are not incorporated in the judgements of liability. Yet it is in the nature of fully private liability rules that all involved agents cannot each bear the entire accident cost. A further problem with the private solution is that liability may exceed the individual's non-human wealth (bankruptcy).

\footnotetext{
7 However, it is safe to conclude that the ranking of these two systems as well as other systems depends on the risky activities in question and the circumstances. For example, the Swedish population, which is homogenous by international standards and the high level of taxes in Sweden may contribute to make the public solution relatively more attractive in Sweden than in many other countries.
} 
These complications, which are generally ignored in idealised models of liability and private insurance, result in actual systems of partial liability and partial insurance. Such a second-best solution is the relevant private alternative; however, it may be possible to improve upon this situation by means of public policy. The fundamental advantage of public policy as compared to the private solution is that government can impose rules that individuals follow because of the government's monopoly on legal violence; insurance may be compulsory and the moral hazard problem may be controlled by mandatory regulation, inspection and punishment.

A common argument in favour of tort-liability is that the costs of accidents are carried by the individual who best knows how to avoid the accident. However, the involved parties often also lack information. As an example of a typical tort, Shavell (1984a) uses the case in which an individual harms someone when rushing to a bus. A regulatory agency would never really know what has happened on the street, Shavell argues. This is certainly true, but who knows the marginal danger involved in running on slippery pavement also occupied by several more or less careful potential victims? The interrelationships between the pedestrians and environmental factors are often so complicated that none has more than fragmentary information about the impact of the behaviour in the specific situation. One problem is that the parties involved in the accident do not communicate before the accident; Demsetz (1972). Thus, they do not know the costs and benefits of potential counter-parties.

However, this lack of knowledge about the impact of care in a unique situation does not exclude information about the impact of safety measures on a more general or aggregated level. For instance, walking instead of running, broader pavements, separate bus refuges and clean or sanded pavements may reduce accidents in a relatively well-known way. This information is a public good available for individuals, insurers, courts and regulatory agencies.

The typical way of solving these problems is public regulation of e.g. speed, bus refuges, size and treatment of pavements etc. Note that the examined public system of insurance and regulation does not require the measurement of costs and their distribution among all involved agents for each separate accident. For instance, a government can offer health care and compulsory sickness insurance benefits that are independent of the specific cause of the injury. The main information required for a proper determination of $A$ and $X^{+}$is confined to how changes in these policy variables affects compliance and aggregate accident costs.

Regulations are upheld by the State's power to punish, and also by the tort-liability system. The courts often use regulations on speed, loading, maximum working hours, bloodalcohol, installed safety-measures etc. as norms for cost-liability. Indeed, many rules are not upheld by penal sanctions at all. Rather, they are standards for cost-liability and thus are part of the tort liability system. One reason is that the regulatory agencies, as well as the court, victims and injurers often have to rely on the same available information about dangerous activities.

A public regulatory system also has disadvantages, of course. The system involves costs of inspection and punishment; Becker (1968). In addition, a government monopoly does not necessarily minimise costs. The political process can result in regulations that favour the political party in power, or pressure groups, rather that the public interest; Stigler(1971), Posner (1974), Peltzman (1976). 


\section{Summary}

In this paper we have examined two systems for regulating externalities and moral hazard. In the private system with insurance, moral hazard can be alleviated by the insurer's power to withhold claims. Transactions costs typically imply that the private system does not eliminate all externalities and risks. The resulting second-best outcome may be improved by an alternative system of public insurance, regulation and punishment of offenders. In the public system with insurance, moral hazard is alleviated by regulation and punishment of offenders. Due to transaction costs, we model this as a costly system of inspection with punishment of detected offenders. Punishments are costly from a social point of view but must often be taken in order to induce proper precautionary behaviour by lawful citizens. The advantages of a public system is that it may apply compulsory insurance as well as regulation, inspection, and punishments that are not available in the private system. Hence, public insurance and regulation are important alternatives and complements to private liability and insurance.

\section{REFERENCES}

BECKER, G. [1968]: "Crime and punishment: An economic approach, The Journal of Political Economy, pp. 169-217.

BROWN, J.P. [1973]: "Towards a theory of liability rules",The Journal of Legal Studies, pp. 323-349.

BURROWS, P. [1984]: "Tort and Tautology: The logic of restricting the scope of liability", The Journal of Legal Studies, vol. XIII (2).

CALABRESI, G. [1970]: The Cost of Accidents, Yale University Press.

COASE, R. [1960]: "The problem of social costs", The Journal of Law and Economics, pp. 1-44.

DEMSETZ, H. [1972]: "When does the rule of liability matter?", The Journal of Legal Studies, pp. 13-28.

GRAVELLE, H.S.E. [1987]: “Accidents, taxes, liability rules and insurance", Geneva Papers in Risk and Insurance, pp. 115-131.

PELTZMAN, S. [1976]: "Toward a more general theory of regulation", The Journal of Law and Economics, 19, pp. 211-240.

POLINSKY, M. and SHAVELL, S. [1979]: "The optimal trade off between the probability and magnitude of fines", The American Economic Review, December, pp. 880-891.

POSNER, R. [1974]: "Theories of economic regulation", The Bell Journal of Economics, 5, pp. 335-358.

SHAVELL, S. [1979a]: "On moral hazard and insurance", Quarterly Journal of Economics, 93, pp. 541-562.

SHAVELL, S. [1979b]: "Accidents, liability and insurance”, Harvard Institute of Economic Research. Discussion Paper no. 685.

SHAVELL, S. [1984a]: "Liability for harm versus regulation of safety", The Journal of Legal Studies, vol. XIII (2), pp. 357-374.

SHAVELL, S. [1984b]: "A model of the optimal use of liability and safety regulation", The Rand Journal of economics, vol 15 (2), pp. 271-280.

SKOGH, G. and STUART, C. [1977]: "Liability, insurance, and the regulation of traffic accidents. In "Law and Economics. Report from a symposium in Sweden"', Acta Societatis Juridicae Lundensis, no. 28, pp. 203-210.

SKOGH, G. [1982]: "Public insurance and accident prevention", The International Review of Law and Economics.

STIGLER, G. [1971]: "The theory of economic regulation", The Bell Journal of Economics, 2, pp. 2-31.

WITTMAN, D. [1977]: "Prior regulation versus post liability: The choice between input and output monotoring", The Journal of Legal Studies, vol. VI (i), pp. 193-212. 